\title{
Multilayer Actuator for Nano Biomedicine
}

\author{
Afonin SM* \\ National Research University of Electronic Technology, Russia \\ *Corresponding author: Afonin SM, National Research University of Electronic Technology, MIET, Moscow, Russia
}

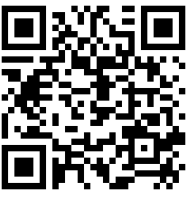

\section{ARTICLE INFO}

Received: 幽 November 06, 2019

Published: 幽 November 12, 2019

Citation: Afonin SM. Multilayer Actuator for Nano Biomedicine. Biomed J Sci \& Tech Res 22(4)-2019. BJSTR. MS.ID.003795.

\section{ABSTRACT}

In this work we determined the mathematical description of multilayer actuator for nano biomedicine. The displacements of the multilayer actuator are received from its mathematical description.

Keywords: Multilayer actuator; Mathematical description

\section{Introduction}

For mathematical description of the multilayer actuator we used the equation of the relative deformation, the mechanical fourterminal scheme and the boundary conditions [1-30].

\section{Mathematical Description Actuator}

The equation $S_{i}$ relative deformation [7-11] has the following form

$$
S_{i}=v_{m i} \Psi_{m}+s_{i j}^{\Psi} T_{j}
$$

where $v_{m i}, \Psi_{m}, s_{i j}^{\psi \prime}, T_{j}$ are parameters

We received the equation the causes force in the form

$$
F=v_{m i} S_{0} \Psi_{m} / s_{i j}^{\Psi}
$$

where $S_{0}$ is the area actuator.

For the mechanical four-terminal scheme [23] actuator we have the matrix in the form.

$$
[M]^{n}=\left[\begin{array}{cc}
\operatorname{ch}(l \gamma) & Z_{0} \operatorname{sh}(\gamma \gamma) \\
\frac{\operatorname{sh}(\gamma \gamma)}{Z_{0}} & \operatorname{ch}(\gamma)
\end{array}\right]
$$

where $l, \gamma$ are length and coefficient.

The mathematical description and diagram on Figure 1 of the multilayer actuator we obtained as the system of the equations in the form

$$
\begin{aligned}
& \Xi_{1}(p)=\left[1 /\left(M_{1} p^{2}\right)\right] \times \\
& \times\left\{-F_{1}(p)+\left(1 / \chi_{i j}^{\Psi}\right)\left[v_{m i} \Psi_{m}(p)-[\gamma / \operatorname{sh}(l \gamma)]\left[\operatorname{ch}(\gamma \gamma) \Xi_{1}(p)-\Xi_{2}(p)\right]\right]\right\}
\end{aligned}
$$

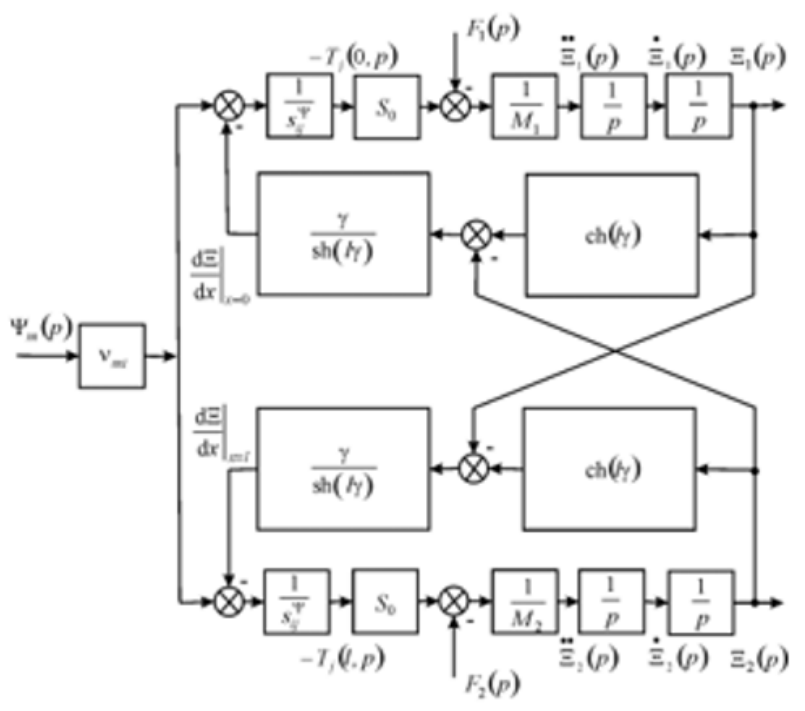

Figure 1: Structural Diagram of Multilayer Actuator.

$$
\begin{aligned}
& \Xi_{2}(p)=\left[1 /\left(M_{2} p^{2}\right)\right] \times \\
& \times\left\{-F_{2}(p)+\left(1 / \chi_{i j}^{\Psi}\right)\left[v_{m i} \Psi_{m}(p)-[\gamma / \operatorname{sh}(\gamma)]\left[\operatorname{ch}(\gamma \gamma) \Xi_{2}(p)-\Xi_{1}(p)\right]\right]\right\} \\
& v_{m i}=\left\{\begin{array}{l}
d_{33}, d_{31}, d_{15} \\
g_{33}, g_{31}, g_{15}, \Psi_{m} \\
d_{33}, d_{31}, d_{15}
\end{array}=\left\{\begin{array}{l}
E_{3}, E_{1} \\
D_{3}, D_{1}, s_{i j}^{\Psi} \\
H_{3}, H_{1}
\end{array}=\left\{\begin{array}{l}
s_{33}^{E}, s_{11}^{E}, s_{55}^{E} \\
s_{33}^{D}, s_{11}^{D}, s_{55}^{D} \\
s_{33}^{H}, s_{11}^{H}, s_{55}^{H}
\end{array}\right.\right.\right.
\end{aligned}
$$




$$
c^{\Psi}=\left\{\begin{array}{l}
c^{E} \\
c^{D} \\
c^{H}
\end{array}, \gamma=\left\{\begin{array}{l}
\gamma^{E} \\
\gamma^{D} \\
\gamma^{H}
\end{array}, l=\left\{\begin{array}{l}
\delta \\
h, \gamma=p / c^{\Psi}+\alpha, \chi_{i j}^{\Psi}=s_{i j}^{\Psi} / S_{0} \\
b
\end{array}\right.\right.\right.
$$

where $\Xi_{1}(p), \Xi_{2}(p), F_{1}(p), F_{2}(p)$ are the Laplace transforms of the displacements and forces for the faces.

From the mathematical description of the multilayer actuator we have the matrix equation

$$
[\Xi(p)]=[W(p)][P(p)]
$$

where $[\Xi(p)],[W(p)],[P(p)]$ are the matrices.

For time $t \rightarrow \infty$ for the inertial load on the two faces of piezoactuator we obtain the expressions of its displacements

$$
\begin{gathered}
\xi_{1}(\infty)=\lim _{p \rightarrow 0} p W_{11}(p)(U / \delta) / p=d_{33} n U M_{2} /\left(M_{1}+M_{2}\right) \\
\xi_{2}(\infty)=\lim _{p \rightarrow 0} p W_{21}(p)(U / \delta) / p=d_{33} n U M_{1} /\left(M_{1}+M_{2}\right) \\
\xi_{1}(\infty)+\xi_{2}(\infty)=d_{33} n U
\end{gathered}
$$

where $n, U$ are the number piezolayers and the voltage.

At $d_{33}=4 \cdot 10^{-10} \mathrm{~m} / \mathrm{V}, n=4, U=100 \mathrm{~V}, M_{1}=1 \mathrm{~kg}, M_{2}=4 \mathrm{~kg}$ we obtained the displacements $\xi_{1}(\infty)=128 \mathrm{~nm}, \xi_{2}(\infty)=32 \mathrm{~nm}, \xi_{1}(\infty)+\xi_{2}(\infty)$ $=160 \mathrm{~nm}$.

\section{Conclusion}

We determined the mathematical description of the multilayer actuator for nano biomedicine. We obtained the displacements of the multilayer actuator from its mathematical description.

\section{References}

1. Schultz J, Ueda J, Asada H (2017) Cellular Actuators. ButterworthHeinemann Publisher, Oxford pp. 382.

2. Afonin SM (2006) Absolute stability conditions for a system controlling the deformation of an elecromagnetoelastic transduser. Doklady mathematics 74(3): 943-948.

3. Zhou S, Yao Z (2014) Design and optimization of a modal-independent linear ultrasonic motor. IEEE transaction on ultrasonics, ferroelectrics, and frequency control 61(3): 535-546.

4. Przybylski J (2015) Static and dynamic analysis of a flextensional transducer with an axial piezoelectric actuation, Engineering structures 84: $140-151$

5. Ueda J, Secord T, Asada HH (2010) Large effective-strain piezoelectric actuators using nested cellular architecture with exponential strain amplification mechanisms. IEEE/ASME Transactions on Mechatronics 15(5): 770-782.

6. Karpelson M, Wei GY, Wood RJ (2012) Driving high voltage piezoelectric actuators in microrobotic applications. Sensors and Actuators A Physical 176: 78-89.

7. Afonin SM (2015) Block diagrams of a multilayer piezoelectric motor for nano- and microdisplacements based on the transverse piezoeffect. Journal of computer and systems sciences international 54(3): 424-439.

8. Afonin SM (2008) Structural parametric model of a piezoelectric nanodisplacement transduser. Doklady physics 53(3): 137-143.

9. Afonin SM (2006) Solution of the wave equation for the control of an elecromagnetoelastic transduser. Doklady mathematics 73(2): 307-313.
10. Cady WG (1946) Piezoelectricity: An introduction to the theory and applications of electromechancial phenomena in crystals. McGraw-Hill Book Company, New York, USA, pp. 806.

11. Mason W (1964) Physical Acoustics: Principles and Methods. Vol.1. Part A. Methods and Devices. Academic Press, New York, USA, pp. 515.

12.Zwillinger D (1989) Handbook of Differential Equations. Academic Press, Boston, USA, pp. 673.

13. Afonin SM (2015) Structural-parametric model and transfer functions of electroelastic actuator for nano- and microdisplacement. Chapter 9 in Piezoelectrics and Nanomaterials: Fundamentals, Developments and Applications. Ed. Parinov IA. Nova Science, New York, USA, pp. 225-242.

14. Afonin SM (2017) A structural-parametric model of electroelastic actuator for nano- and microdisplacement of mechatronic system. Chapter 8 in Advances in nanotechnology. Volume 19. Eds. Bartul Z, Trenor J, Nova Science, New York, USA, pp. 259-284.

15. Afonin SM (2012) Nano- and micro-scale piezomotors. Russian engineering research 32(7-8): 519-522.

16. Afonin SM (2007) Elastic compliances and mechanical and adjusting characteristics of composite piezoelectric transducers. Mechanics of solids 42(1): 43-49.

17. Afonin SM (2014) Stability of strain control systems of nano-and microdisplacement piezotransducers. Mechanics of solids 49(2): 196207.

18. Afonin SM (2017) Structural-parametric model electromagnetoelastic actuator nanodisplacement for mechatronics. International Journal of Physics 5(1): 9-15.

19. Afonin SM (2017) Structural-parametric model of piezoactuator nanoand microdisplacement for nanoscience. AASCIT Journal of Nanoscience 3(3): $12-18$

20. Afonin SM (2016) Solution wave equation and parametric structural schematic diagrams of electromagnetoelastic actuators nano- and microdisplacement. International Journal of Mathematical Analysis and Applications 3(4): 31-38.

21. Afonin SM (2018) Structural-parametric model of electromagnetoelastic actuator for nanomechanics. Actuators 7(1): 1-9.

22. Afonin SM (2016) Structural-parametric models and transfer functions of electromagnetoelastic actuators nano- and microdisplacement for mechatronic systems. International Journal of Theoretical and Applied Mathematics 2(2): 52-59.

23. Afonin SM (2017) Parametric block diagrams of a multi-layer piezoelectric transducer of nano- and microdisplacements under transverse piezoelectric effect. Mechanics of Solids 52(1): 81-94.

24. Afonin SM (2018) Multilayer electromagnetoelastic actuator for robotics systems of nanotechnology, Proceedings of the 2018 IEEE Conference EIConRus: 1698-1701.

25. Afonin SM (2018) Electromagnetoelastic nano- and microactuators for mechatronic systems. Russian Engineering Research 38(12): 938-944.

26. Afonin SM (2018) Structural-parametric model of electro elastic actuator for nanotechnology and biotechnology. Journal of Pharmacy and Pharmaceutics 5(1):8-12.

27. Afonin SM (2018) Electromagnetoelastic actuator for nanomechanics. Global Journal of Research in Engineering. A: Mechanical and Mechanics Engineering 18(2): 19-23.

28. Afonin SM (2019) Actuator for nano biomedical research. Biomedical Journal of Scientific and Technical Research 19(3): 14300-14302.

29. Afonin SM (2019) Absolute stability of control system with electro magneto elastic actuator for nanobiomedicine. Biomedical Journal of Scientific and Technical Research 21(4): 16027-16030.

30. Bhushan B (2004) Springer Handbook of Nanotechnology. Ed. by Springer, Berlin, New York, USA, pp. 1222. 


\section{ISSN: 2574-1241}

DOI: 10.26717/BJSTR.2019.22.003795

Afonin SM. Biomed J Sci \& Tech Res

CC (P) This work is licensed under Creative

Submission Link: https://biomedres.us/submit-manuscript.php

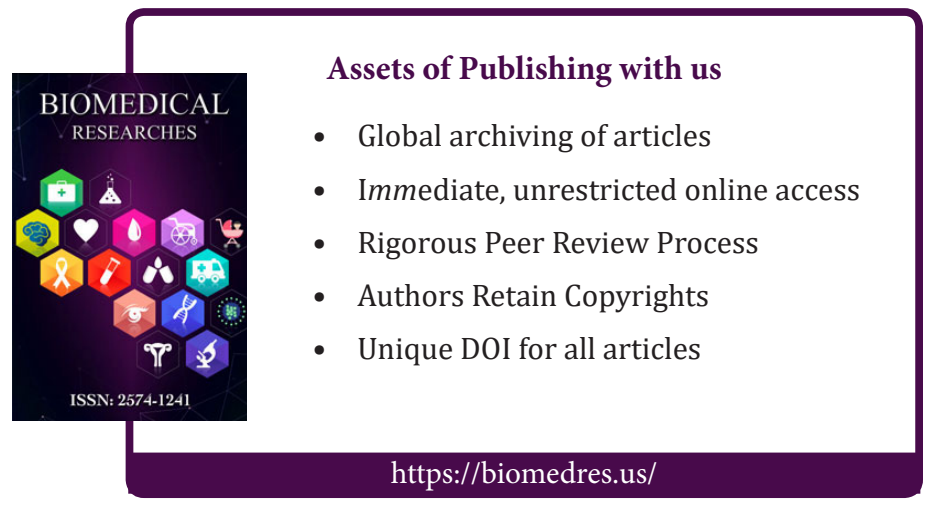

